\title{
Study of Wear Properties of Al-SiC Composites
}

\author{
Manoj Singla ${ }^{1}$, Lakhvir Singh ${ }^{2}$, Vikas Chawla ${ }^{3}$ \\ ${ }^{1}$ Department of Mechanical Engineering, R.I.E.I.T., Railmajra, Distt. Nawanshahr (Pb.)- \\ 144533, INDIA \\ ${ }^{2}$ Department of Mechanical Engineering, BBSBEC, Fatehgarh Sahib (Pb.), INDIA \\ ${ }^{3}$ Department of Materials \& Metallurgical Engineering, I.I.T. Roorkee (Uttaranchal), INDIA \\ Contact: $\underline{\text { manojsingla77@gmail.com }}{ }^{1}, \underline{\text { Ivs1@rediffmail.com }}{ }^{2}$, vikkydmt@iitr.ernet.in $^{3}$
}

\begin{abstract}
Al-SiC composites containing four different weight percentages 5\%, 10\%, 20\% and 25\% of SiC have been fabricated by liquid metallurgy method. Friction and wear characteristics of Al-SiC composites have been investigated under dry sliding conditions and compared with those observed in pure aluminium. Dry sliding wear tests have been carried out using pin-on-disk wear test rate normal loads of 5, 7, 9 and $11 \mathrm{Kgf}$ and at constant sliding velocity of 1.0m/s. Weight loss of samples was measured and the variation of cumulative wear loss with sliding distance has been found to be linear for both pure aluminium and the composites. It was also observed that the wear rate varies linearly with normal load but lower in composites as compared to that in base material. The wear mechanism appears to be oxidative for both pure aluminium and composites under the given conditions of load and sliding velocity as indicated by scanning electron microscope (SEM) of the worn surfaces. Further, it was found from the experimentation that the wear rate decreases linearly with increasing weight fraction of silicon carbide and average coefficient of friction decreases linearly with increasing normal load and weight fraction of SiC. The best results have been obtained at 20\% weight fraction of 320 grit size SiC particles for minimum wear.
\end{abstract}

Key Words: $\quad$ Metal Matrix Composites MMC's, Silicon Carbide SiC 


\section{INTRODUCTION}

A composite material is a 'material system' composed of a combination of two or more micro or macro constituents that differ in form, chemical composition and which are essentially insoluble in each other.

The motto to design MMCs is to combine the metals \& ceramics i.e. addition of high strength, high modulus refractory particles to ductile metal matrix to get tailor made properties.

In the present work, an effort has been made to study wear properties with varying weight fraction of SiC in particle reinforced MMCs developed with the help of two - step mixing method of stir casting technique.

\section{EXPERIMENTAL PROCEDURE}

The standard samples Fig. 2 (pins - cylindrical shape) have been prepared (Ø8mm X 25 mm ) out of castings (Fig. 1) having different wt. \% of SiC.

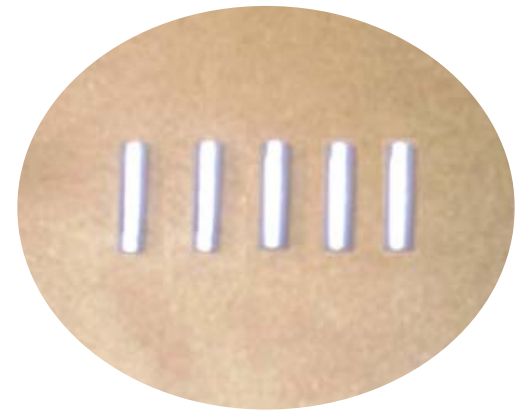

Figure 1. Pictorial view casting of sample containing different $\% \mathrm{SiC}$ by weight

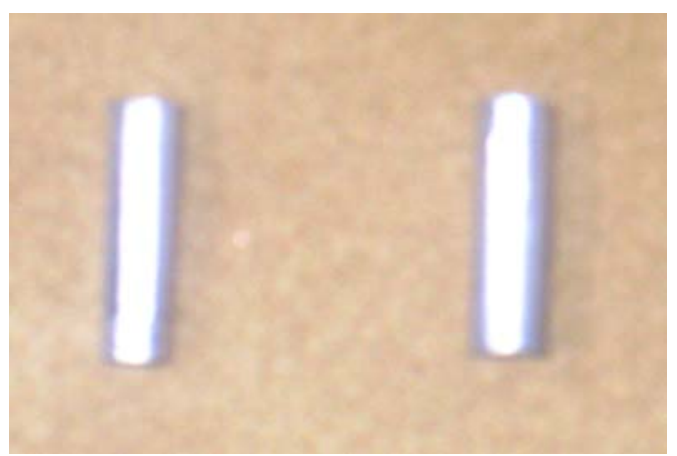

Figure 2. Standard samples for wear test

\subsection{Wear Test}

Dry sliding wear tests for the aluminium \& composites have been conducted using pin-on-disc machine model TR - 20 supplied by M/S Ducom , Bangalore (India). The tests have been conducted in air. Wear tests have been conducted using cylindrical samples (Ø8mm X $25 \mathrm{~mm}$ ) that had flat surfaces in contact region and the rounded corner. The pin is held stationary against 
the counter face of a 100mm diameter rotating disc made of En-32 steel having a hardness of HRC65 as provided on pin-on-disc machine. The wear tests have been conducted under the four normal loads 50, 70, 90, $110 \mathrm{~N}$ and at fixed sliding speed of $1.0 \mathrm{~m} / \mathrm{s}$. Each wear test has been carried out for a total sliding distance of $1.8 \mathrm{~km}$. Tangential force has been monitored continuously. Pin weight loss has been measured at intervals of 5 minutes to determine wear loss. Weight loss data has been converted to volume loss data using the density of pure aluminium $2680 \mathrm{~kg} / \mathrm{m} 3$ and density of $2688 \mathrm{~kg} / \mathrm{m} 3,2698 \mathrm{~kg} / \mathrm{m} 3,2718 \mathrm{~kg} / \mathrm{m} 3 \& 2726 \mathrm{~kg} / \mathrm{m} 3$, respectively, for the composites having 5\%, 10\%, 20\% \& 25\% SiC contents, respectively. The pin is removed from the holder after each run, properly cleaned using acetone. The weight loss has been taken in a digital balance having least count of $1 \mathrm{mg}$. The pin weight is measured after every 5 min of sliding and six data points have been taken in a total duration of $30 \mathrm{~min}$. Disk has been cleaned with acetone after each run to remove debris.

The friction coefficients have been determined from the friction force and normal loads.

\subsection{SEM Study of Composite Samples}

SEM analysis of the post mechanical tests was carried out to study the worn out surfaces under different applied loads.

SEM analysis was done on JOEL make SEM at Sophisticated Analytical Instrumentation Facility, Central Instrumentation Laboratory, Panjab University, Chandigarh.

\section{RESULTS AND DISCUSSION}

\subsection{Results}

Fig. $3(\mathrm{a}-\mathrm{e})$ shows the variation of cumulative wear volume with sliding distance under different loads and at fixed sliding velocity of $1.0 \mathrm{~m} / \mathrm{s}$ for pure aluminium (S1) and composites S2, S3, S4, S5, respectively. It is observed that the volume loss increases linearly with increasing sliding distance. However the cumulative volume loss of composites is lower than that observed in pure $\mathrm{Al}$ and decreases with increasing volume fraction of $\mathrm{SiC}$ up to $20 \%$ as is evident from Fig. 3 (bd) and there after for $25 \% \mathrm{SiC}$ wear loss again increases slightly \& thus reverses the trend of decreasing wear volume loss with increase in $\mathrm{SiC}$ weight \%. This trend is due to clustering of $\mathrm{SiC}$ particles and then due to increase in weight settling down at the bottom \& non - uniform mixing in $\mathrm{Al}$ matrix.

Fig. 4 shows the variation of cumulative wear volume with normal applied loads \& volume loss is increasing with increasing normal loads. Wear volume loss is maximum for pure aluminium \& then decreases as the \% $\mathrm{SiC}$ increases upto $20 \%$ again this trend changes for $25 \% \mathrm{SiC}$ content because of non-uniform mixing. 

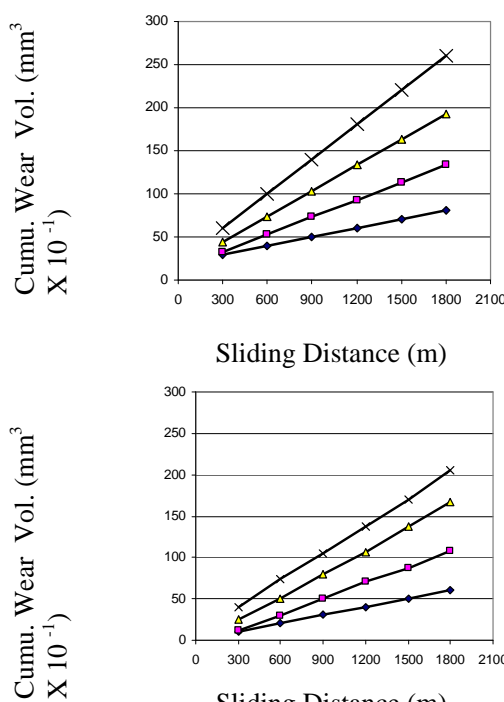

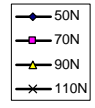

Sliding Distance (m)

(a)

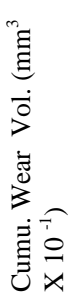

(c)

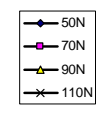

Sliding Distance (m)

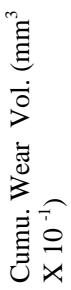

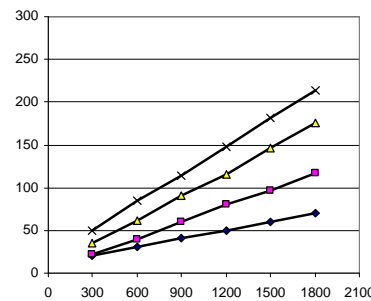

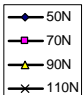
Sliding Distance (m)

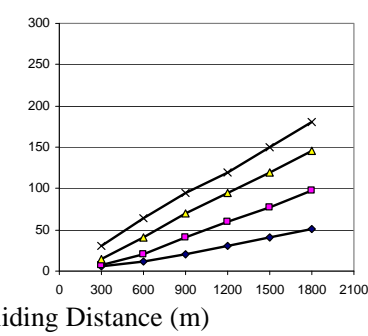

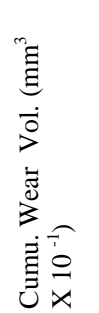
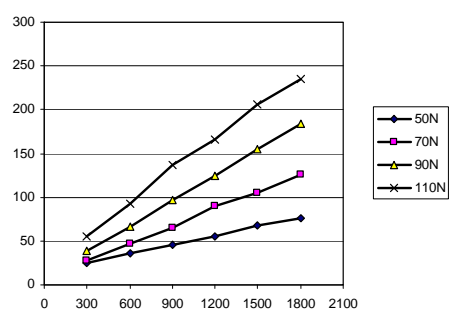

Sliding Distance (m)

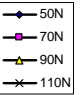

(d)

(b)

(e)

Fig. 3. Variation of cumulative volume loss with sliding distance

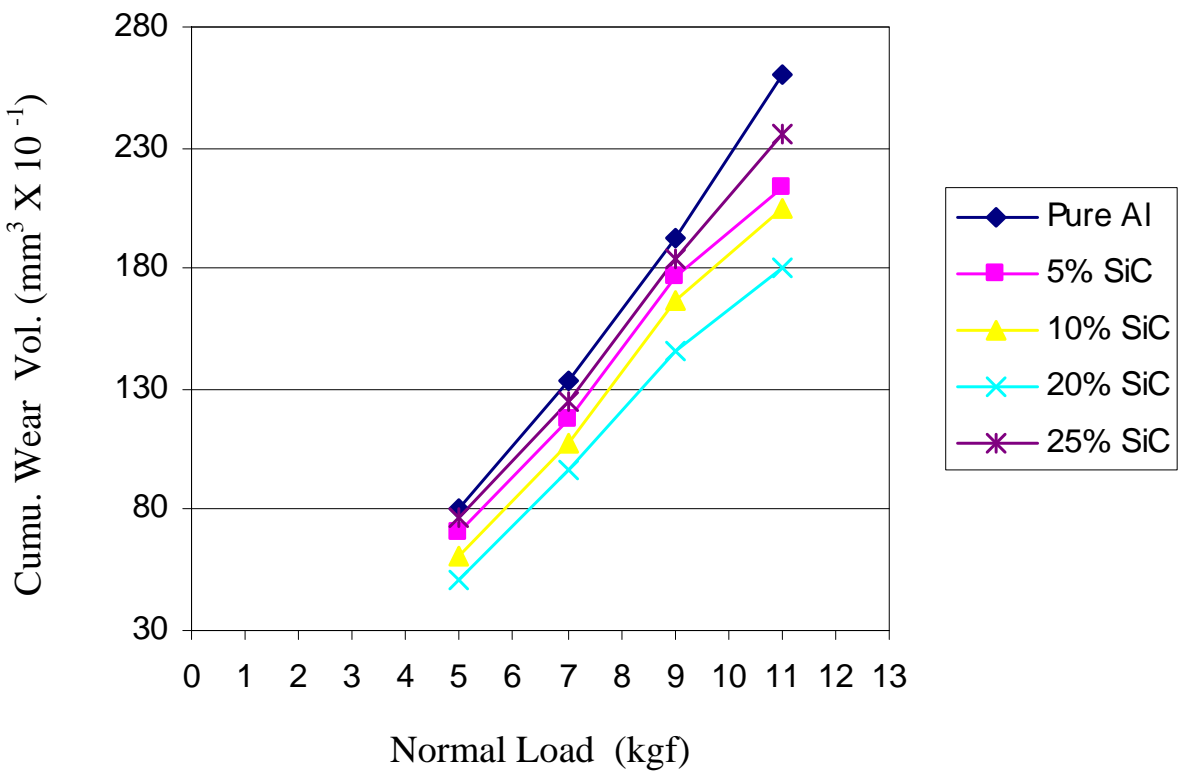

Fig. 4 Variation of cumulative volume loss with normal load 
Fig. 5 (a-e) shows the variation of coefficient of friction with sliding distance, friction coefficients fluctuates around the mean level and decreases as the sliding progresses. This trend is similar in all the materials. The fluctuations in the coefficient of friction may be due to variation in contact between sample and disk. Composites have shown lower coefficient of friction in comparison to pure aluminum.

Fig. 6 shows the variation of average coefficient of friction with increasing load. It is observed that average coefficient of friction decreases linearly with increasing load. Average value of coefficient of friction for pure $\mathrm{Al}$ is 0.6 \& for composites decreases as the \% $\mathrm{SiC}$ increases. Coefficient of friction for $25 \% \mathrm{SiC}$ composite fluctuates between coefficient of friction for $5 \%$ (S1) \& $10 \%$ (S2) SiC .
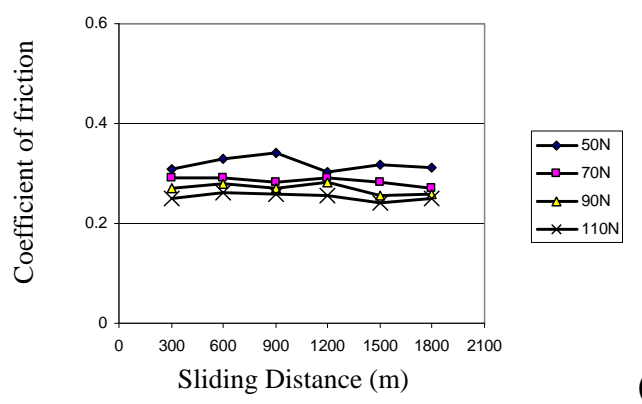

(a)
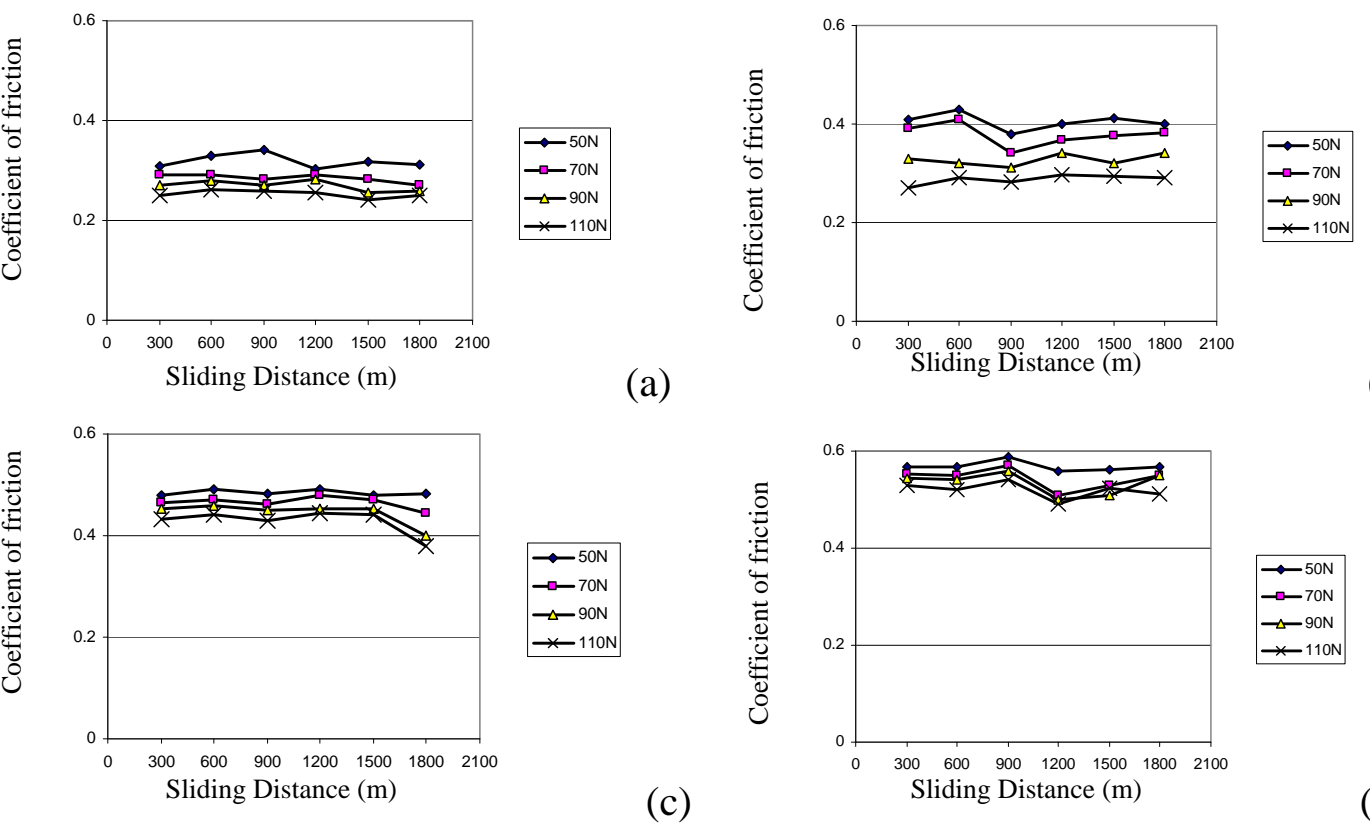

(c)

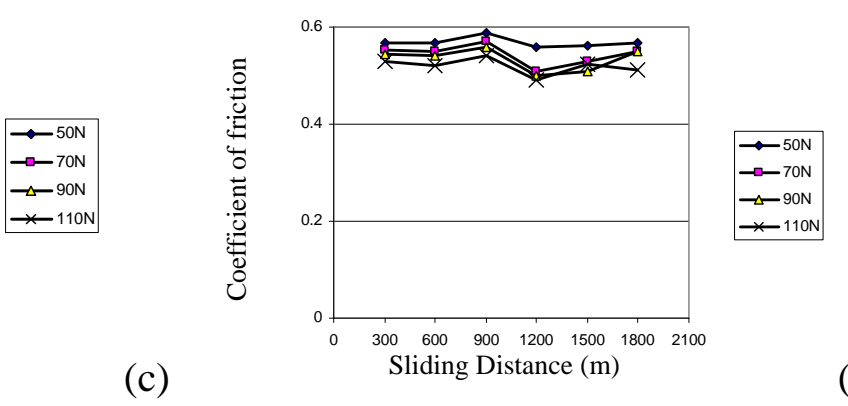

(b)

(d)

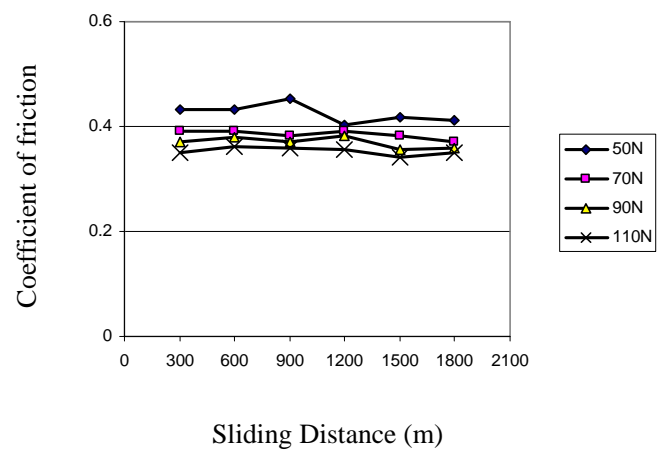

(e)

Fig. 5 Variation of Coefficient of Friction with sliding distance 


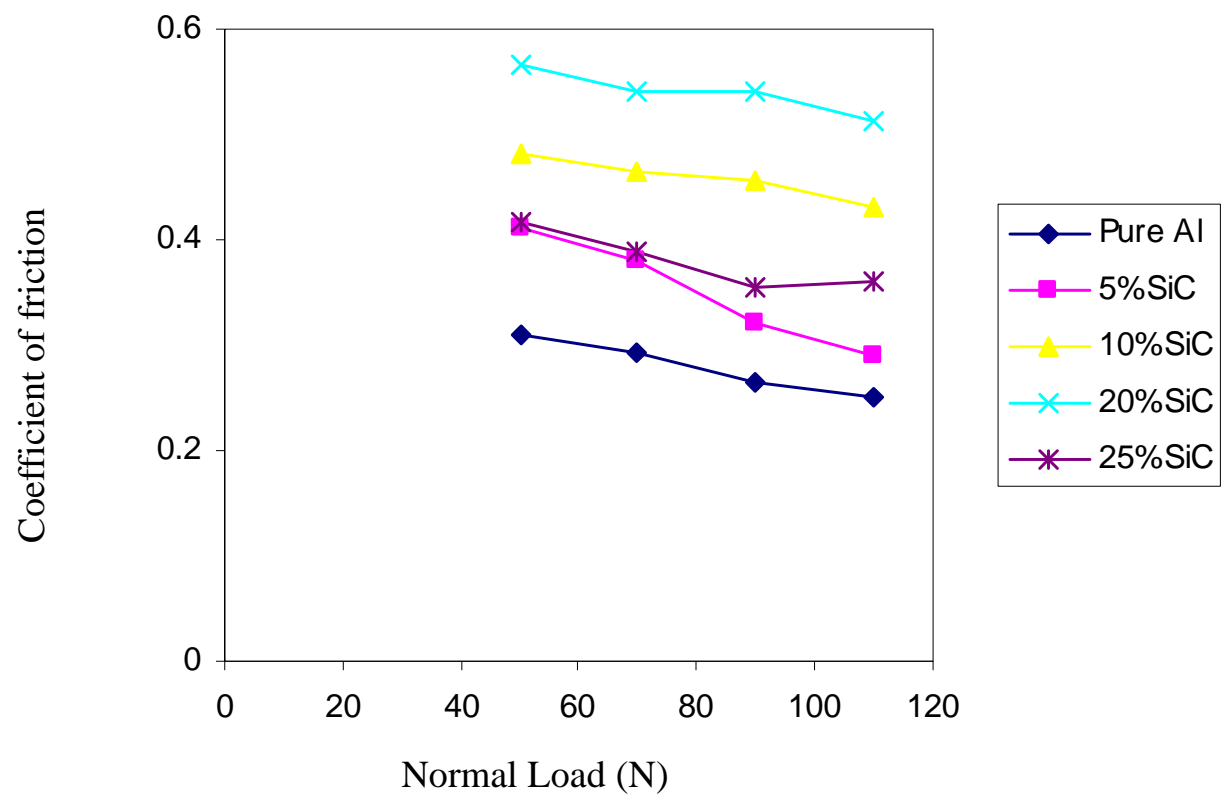

Fig. 6 Average Coefficient of Friction Vs Load

\subsection{Discussions}

\subsubsection{Wear of worn surfaces}

Fig. 7 (a-d) shows the scanning electron micrograph of worn surfaces of pure aluminium under different applied loads.

Fig. 8 (a-d) shows the scanning electron micrograph of worn surfaces of $\mathrm{Al}-20 \% \mathrm{SiC}$ composite. A transfer layer of compacted wear debris along with the wear tracks can be observed over the sliding surface. This layer reaches a critical thickness before being detached resulting eventually in generation of wear debris. The extent of cover provided by this transfer layer is determined by the load, sliding speed and it increases with increasing load because of the increased frictional heating and hence better compaction. The other reason for lower wear rate in composites is their high hardness as compared to pure aluminum resulting in lower real area of contact and therefore lower wear rate. 


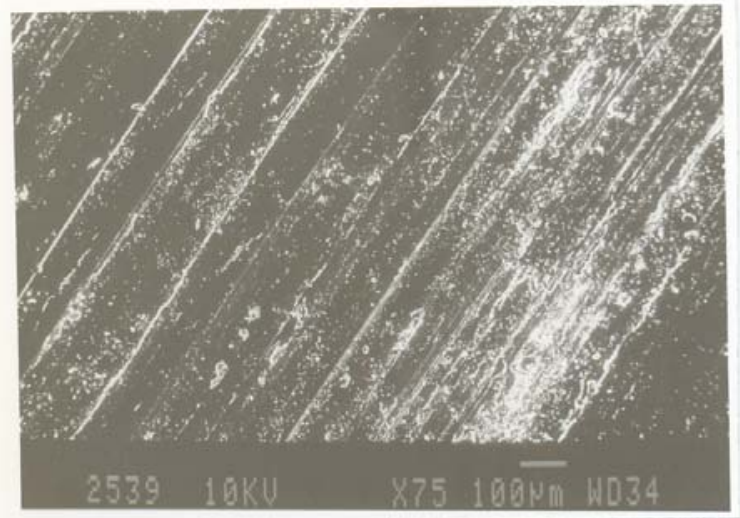

(a) $50 \mathrm{~N}$

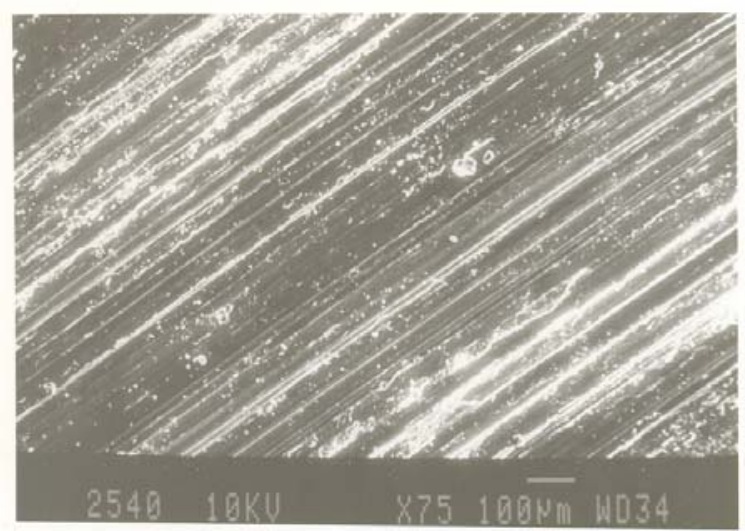

(c) $90 \mathrm{~N}$

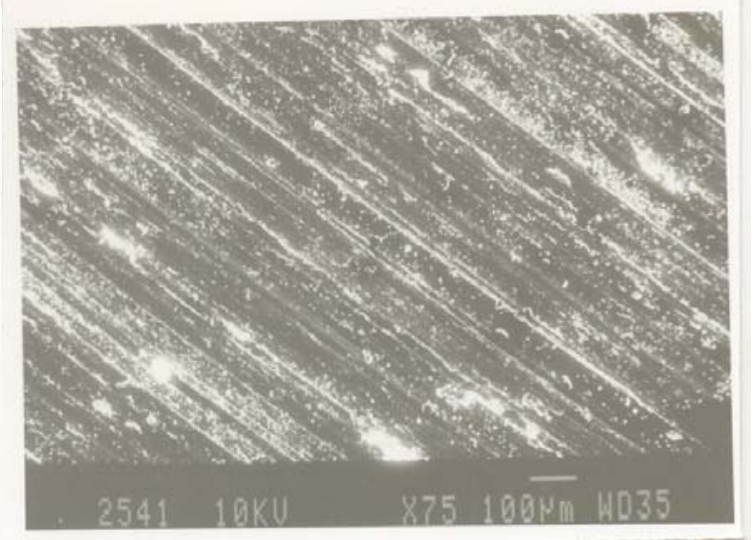

(b) $70 \mathrm{~N}$

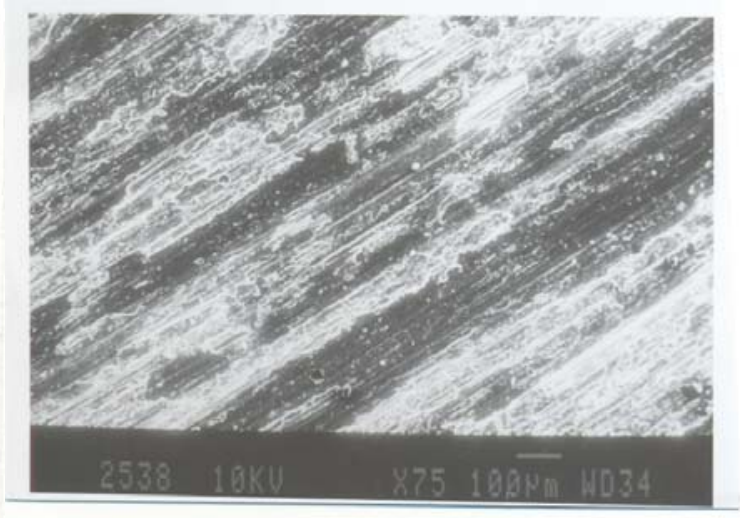

(d) $110 \mathrm{~N}$

Fig. 7. Scanning Electron Micrographs of worn surfaces of Pure Al. 


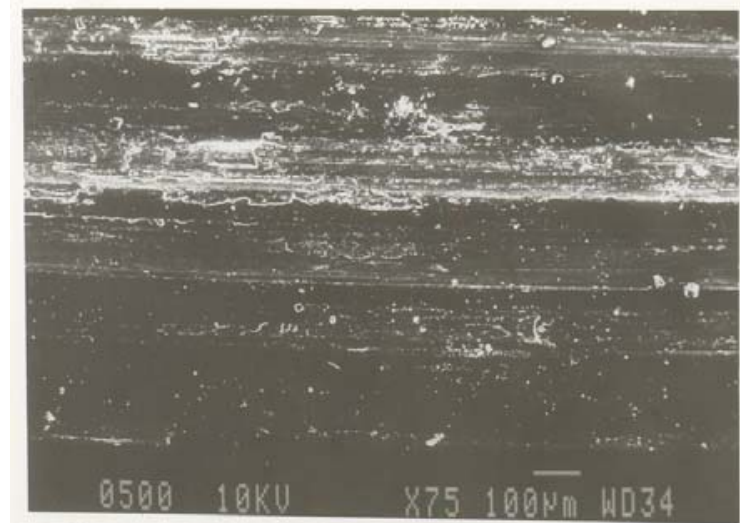

(a) $50 \mathrm{~N}$

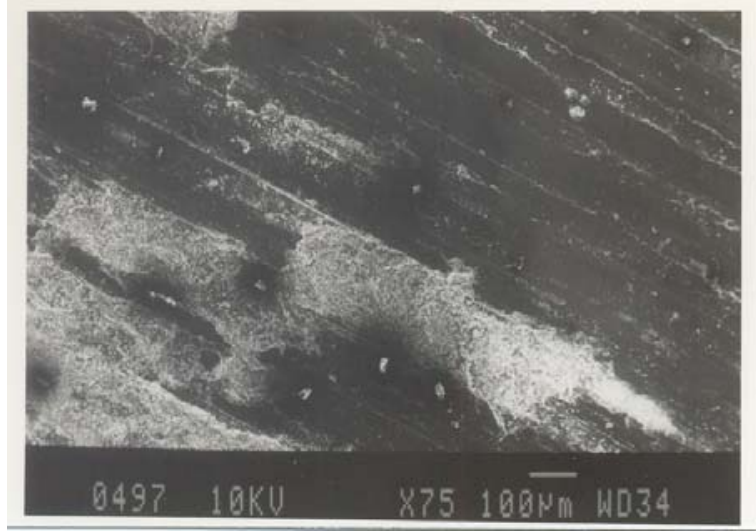

(c) $90 \mathrm{~N}$

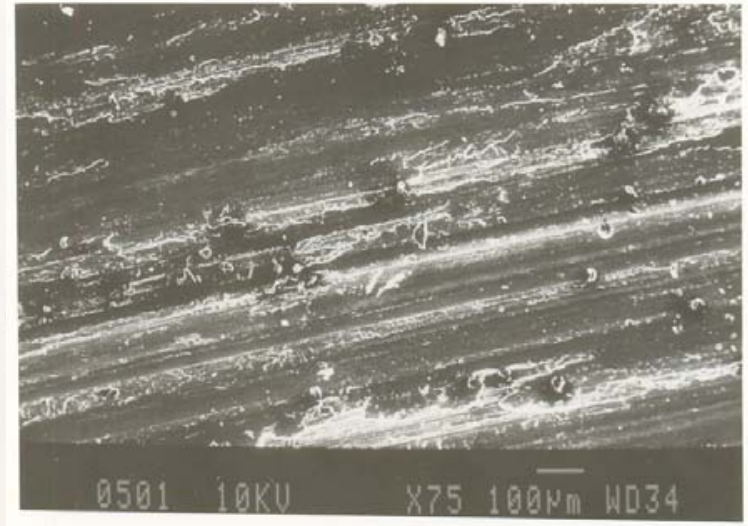

(b) $70 \mathrm{~N}$

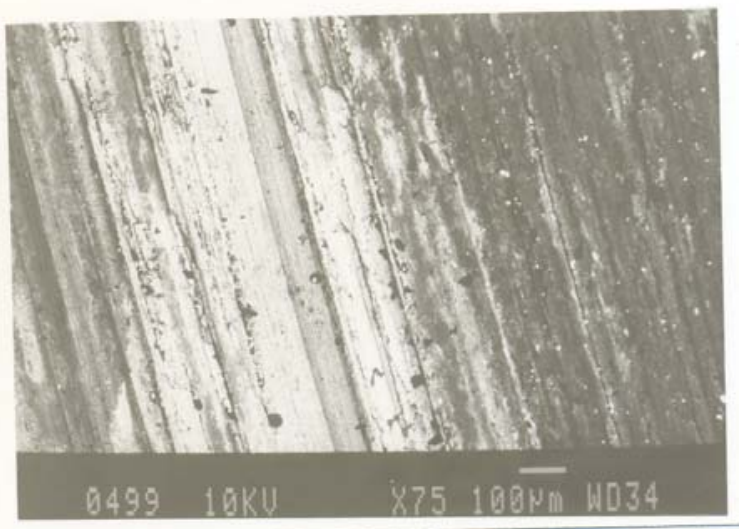

(d) $110 \mathrm{~N}$

Fig. 8. Scanning Electron Micrographs of worn surfaces of Al- 20\% SiC.

\section{CONCLUSIONS}

The experimental study reveals following conclusions:

1. For a given load, the cumulative wear volumes of composites and pure aluminium pins increase linearly with sliding distance under dry sliding.

2. The wear rate increases linearly with the increase in normal load. However, the composites have shown a lower rate of wear (up to $20 \% \mathrm{SiC}$ ) as compared to that observed in pure aluminium.

3. The average coefficient of friction decreases with increasing load in both pure aluminium and composites. However, the composites show a lower coefficient of friction than that observed in pure aluminium. 


\section{ACKNOWLEDGEMENT}

The author acknowledges with thanks the support provided by Department of Mechanical Engineering, RIEIT, Railmajra, Distt. Nawanshahr \& BBSBEC, Fatehgarh Sahib for carrying out the experimentation work.

\section{REFERENCES}

1. Naher, S., Brabazon, D. and Looney, L. (2003), "Simulation of the stir casting process", Journal of Materials Processing Technology, Vol. 143-144, pp. 567-571.

2. Balasivanandha, S., Kaarunamoorthy, L., Kaithiresan, S. and Mohan, B. (2006), "Influence of stirring speed and stirring time on distribution of particles in cast metal matrix composite", Journal of Material Processing Technology, Vol. 171, pp. 268-273.

3. Chen. M.Y. (2002), "Friction behaviour of co- continuous alumina/aluminium composites with \& without SiC reinforcement”, Wear, Vol. 249, pp. 868-876.

4. Dasgupta Rupa, (2005) "SiC particulate dispersed composites of an $\mathrm{Al}-\mathrm{Zn}-\mathrm{Mg}-\mathrm{Cu}$ alloy:Property comparison with parent alloy”, Material Characterization, Vol. 54, pp. 438445.

5. Hashim. J. (19990, "Metal matrix composites: production by stir casting method”, Journal of Material Processing Technology, Vol. 92-93, pp. 1-7.

6. Lim. S.C., Gupta M., Ren. L., Kwok. J.K.M., “ The tribological properties of Al-Cu/SiCp metal-matrix composites fabricated using the rheocasting technique”, Journal of Materials Processing Technology, Vol. (89-90), pp. 591-596..

7. Mares, M. (2001), “ Some issues on tailoring possibilities for mechanical properties of particulate reinforced metal matrix composites” Journal of Optoelectronics and Advanced Materials, Vol. 3 (1), pp. 119 - 124.

8. Min Zhao, Gaohui Wu, Longtao Jiang, Zuoyong Dou,(2005) “ Friction and wear properties of $\mathrm{TiB}_{2 \mathrm{P}} / \mathrm{Al}$ Composite”, Composites Part: applied science and manufacturing,

9. Naher, S., Brabazon, D. and Looney, L. (2004), "Development and assessment of a new quick quench stir caster design for the production of metal matrix composites”, Journal of Material Processing Technology, Vol. 166, pp. 430-439.

10. Rajnesh, T. (2005), "Synthesis and tribological characterization of in-situ cast Al-TiC composites”, Journal of Wear, 259, pp. 569-576.

11. Rohatgi, P.K., Sobezak, J., Asthana, R. and Kim, J.K.(1998), "Inhomogeneities in silicon carbide distribution in stirred liquids-water model study for synthesis of composites", Materials Science and Engineering, Vol.252 (1), pp. 98-99. 